\title{
Gender Differences in Occupational Mobility - Evidence from Portugal
}

\author{
Nuno Crespo*, Nadia Simoes ${ }^{* *}$ and Sandrina B. Moreira ${ }^{* * *}$
}

\begin{abstract}
*Instituto Universitário de Lisboa (ISCTE - IUL), ISCTE Business School Economics Department, BRU - IUL (Business Research Unit), Lisboa, Portugal.

*** Instituto Universitário de Lisboa (ISCTE - IUL), ISCTE Business School Economics Department, BRU - IUL (Business Research Unit), Lisboa, Portugal.

${ }^{* * * *}$ Instituto Politécnico de Setúbal (ESCE - IPS), Department of Economics and Management, Setúbal, Portugal and BRU - IUL (Business Research Unit), Lisboa, Portugal.
\end{abstract}

\begin{abstract}
In this paper we evaluate if gender influences the pattern of upward and downward occupational mobility. With data for Portugal in the period 1998-2009, we find that women have a lower probability of upward mobility and a higher probability of downward mobility. The results also reveal the importance of some other determinant factors, especially education and initial occupation. Additionally, considering an analysis by quartiles (taking as reference a ranking based on average wages), we confirm that the determinants of occupational mobility depend on the ranking of the initial occupation. This analysis allows us to conclude that the unfavorable pattern of occupational mobility in the case of women is due, essentially, to the disadvantage they have at the bottom of the distribution. On the contrary, in the top occupations, the results suggest the existence of equality between genders.
\end{abstract}

Key words: Occupational mobility, Gender, Determinant factors, Portugal.

JEL Codes: J24, J62

\section{Introduction}

Occupations are an extremely important determinant of workers' quality of life. This importance derives, on the one hand, from the strong correlation between occupations and wages, which directly affect the workers' social status and levels of consumption and, on the 
other hand, from the importance of occupations for workers' personal realization (Harper and Haq, 1997).

Most studies on occupational mobility have two main objectives. The first is to quantify the magnitude of mobility and characterize its main facets (Evans, 1999; Moscarini and Thomsson, 2007; Kambourov and Manovskii, 2008; Longhi and Brynin, 2010; Lalé, 2012). The second is to explore the determinants of mobility decisions. Three determinants have received special attention: human capital, business cycle, and nationality.

Nevertheless, there are other important factors to explain the decisions of occupational mobility. In this context, gender assumes an important role. We can identify some arguments suggesting that there are significant differences between genders concerning occupational mobility. First, it is possible to detect differences stemming from distinct labor market behaviors, namely concerning job search and quit decisions. Second, additional differences arise from the obstacles associated with occupational segregation, i.e., unequal distribution of men and women in the different occupations, creating limitations on the chances of upward and downward mobility for both genders.

We use data from the Portuguese Labor Force Survey, covering a period of twelve years (1998-2009). Concerning the Portuguese economy, there is some research on certain types of labor mobility, namely on job mobility (Vieira, 2005), wage mobility (Vieira and Madruga, 2004), and the link between these two types of mobility (Martins, 2011), but to the best of our knowledge there is no detailed analysis of the magnitude and determinants of occupational mobility for Portugal.

The main goal of this paper is to explore the relationship between occupational mobility and gender in the Portuguese case. In addition, our analysis has three complementary goals. First, contributing to fill the gap above identified concerning the lack of studies on occupational mobility in the Portuguese case, we provide evidence on the issue. Second, we examine the 
importance of other determinants of upward and downward occupational changes. Third, we develop an analysis by quartiles in order to evaluate if the determinants of occupational mobility are affected by the hierarchical position of the initial occupation.

The paper is structured as follows. In the next section, we provide an overview of the literature on occupational mobility and, more specifically, we discuss the main arguments that point to important differences between genders. Following, we describe the data and provide empirical evidence. Then, we present the model and discuss the results regarding the determinants of occupational mobility in the overall sample and by quartiles. The last section provides some final remarks.

\section{Theoretical Background}

\section{Occupational mobility}

The trajectories of occupational mobility can be divided into two groups: those related to the natural process of career progression and the remaining ones, which can be associated with the wish of the individuals to experience other occupations more adequate to their preferences and abilities, with an opportunity that may arise or in anticipation to the risk of job loss due to unfavorable economic conditions (the evolution of the business cycle, structural changes, among other aspects).

Occupational changes related to career evolution probably represent the access to better working conditions, including wages, job security, and autonomy. However, other occupational changes have a different nature, raising potential problems associated with the transferability of human capital. The characteristics and the quantity of human capital accumulated by the workers are critical factors in the decision of occupational change 
(Sicherman and Galor, 1990; Dolton and Kidd, 1998). Over the lifecycle, individuals make several decisions regarding the accumulation of different types of human capital - general, occupation-specific, industry-specific, firm-specific, and job-specific. All these types of human capital affect the net benefits associated with alternative career pathways. In the case of occupation-specific human capital, the impact on mobility depends on the transferability of occupational skills. In fact, skills not transferable to other occupations are a significant constraint to occupational mobility.

Occupational mobility can also be affected by the business cycle. Evans (1999) points out that during recessions, downward occupational mobility is a common strategy to avoid unemployment when the probability of job loss is significant. This strategy involves an important risk, however. The performance of a less qualified activity during a given period may jeopardize the return to the initial occupation.

\section{Occupational Mobility and Gender}

There are several arguments supporting the belief that the pattern of occupational mobility is different between men and women. In this section, we highlight five groups of arguments.

Employment contracts: the growth of temporary work is a trend in OECD countries over the past 30 years (OECD, 2007). Several studies point to an over-representation of women in non-standard forms of employment (Petrongolo, 2004). Therefore, it is reasonable to expect higher levels of occupational mobility in this group for two main reasons. First, this type of contract generates a higher turnover rate. Second, since more precarious workers receive less training (Arulampalam and Booth, 1998), they have less to lose with occupational changes. 
Migrations and "tied movers": earlier studies suggest that couples that decide to migrate are mainly motivated by an opportunity for the husband. Frequently, wives are "tied movers" as emphasized by Taylor (2007). Therefore, it is possible that wives experience a deterioration of their situation regarding earnings (Blackburn, 2010) and the probability of employment (Boyle et al., 2001).

Job search: a third element that contributes to the difference between men and women concerning occupational mobility is related to their job search behavior. The genders differ in terms of: (a) the channels of job search, (b) the use of these channels, and (c) the intensity of job search.

Regarding the job search channels, it is important to stress the differences between the two genders in terms of networks of informal contacts. This is important because a considerable number of jobs are obtained through friends and relatives (Ioannides and Loury, 2004). However, social networks are a channel of gender inequality. Earlier research shows that women have a lower density network of social contacts than men (van der Leij and Buhai, 2008). Additionally, men's social networks are more diversified and include more powerful and work-centered contacts (Campbell, 1988). The disadvantage of women in this regard can be explained by two reasons. First, due to family responsibilities, women have less time to invest in networking, being their contacts based essentially on family and friends. Second, since women have lower-status jobs, their work-related contacts are less powerful. Another element of gender differentiation in the process of job searching is related to the fact that women tend to prefer formal methods of job search with consequences in terms of labor market outcomes (Campbell and Rosenfeld, 1985).

A final element of differentiation between men and women is the job search intensity. When employed, women tend to search less intensively for a new job (Keith and McWilliams, 
1999). There are several explanations for this behavior. First, the opportunity cost of job searching is greater for women because, on average, they are responsible for a larger share of household work. Second, recent studies indicate that women are less competitive and more risk averse than men (Niederle and Vesterlund, 2007; Croson and Gneezy, 2009). This is an important distinction because the job search process is eminently competitive.

Quit behavior: the empirical literature on labor turnover shows that the quit behavior varies markedly between genders. It is important to distinguish two types of transitions: job-to-job and job-to-nonemployment transitions. Women are more likely to realize job-tononemployment transitions, due to family related reasons (marriage or childbirth), and less likely to realize job-to-job transitions (Frederiksen, 2008). The explanation for the lower incidence of women in job-to-job transitions is associated with their lower job search intensity, discussed above. However, another important factor is derived from the link between job satisfaction and quits. The degree of job satisfaction is a strong predictor of separations and quits, as emphasized, for instance, by Clark (2001). As women reveal higher levels of job satisfaction than men (Clark, 1997), a lower degree of occupational mobility is expectable in the case of women.

Occupational segregation: the unequal distribution of women and men by different occupations and hierarchical positions has been studied extensively, regarding both its causes and implications. Occupational segregation corresponds to a segmented perspective of the labor market between "female jobs" and "male jobs" (Bergmann, 1974). In comparison with "male jobs", "female jobs" are characterized by low earnings, low training, and fewer opportunities for upward mobility. This separation between "female" and "male jobs" affects 
the process of job selection given the institutional and cultural barriers between the two groups of jobs (Tomaskovic-Devey and Skaggs, 2002).

\section{Data and empirical evidence}

We use quarterly data from the Portuguese Labor Force Survey, carried out by the National Statistics Office, covering the period between 1998:01 and 2009:04 (48 quarters). The use of quarterly data (instead of annual data as in most studies on this subject) is advantageous because it minimizes time aggregation (Moscarini and Thomsson, 2007; Moscarini and Vella, 2008).

The database contains information about the socio-demographic characteristics of the individuals, their levels of human capital, and their current and past labor market situation. Additionally, it allows us to monitor the occupational changes, at the two-digit level, for a representative sample of Portuguese workers.

Our sample includes 282,438 individuals, aged 15-64, living in continental Portugal. Following a common procedure, we exclude individuals: (i) in self-employment; (ii) working in the agricultural sector; (iii) working in the military sector; and (iv) in part-time employment (less than 30 hours per week). We also confine our analysis to the main paid jobs. Finally, following Zangelidis (2008), we consider both intra- and inter-firm occupational changes.

The analysis of vertical occupational mobility requires a criterion to rank occupations. One possibility would be to use standard occupational schemes (SOC), which has an "implied hierarchy built into their classification" (Dex et al., 2007, p. 4). However, the occupations included in each major level still reveal a considerable degree of heterogeneity. It is therefore preferable to use an alternative criterion. A common method is to use average hourly wages. 
As argued by Wright and Dwyer (2003), wages correspond to the most consequential and reliable measurable indicator of an occupation quality. We follow this option in the present study. Table 1 shows the ranking of the occupations from the highest paid to the lowest paid, considering average wages corrected for inflation in the period considered.

\section{[Table 1]}

As seen in Table 1, there is a marked difference in wage terms between the various occupations, especially at the top of the occupational ranking. To that extent, occupational changes may imply significant (positive or negative) changes in terms of well-being and quality of life of the individuals.

Following the occupational ranking shown in Table 1 and considering simultaneously the whole sample and sub-samples divided by gender, Table 2 shows, for each occupation, information on the magnitude of total, upward, and downward mobility.

\section{[Table 2]}

The evidence shows that the occupations with the highest level of occupational mobility are General managers $\left(11^{\text {th }}\right.$ in the occupational ranking), Legislators and senior officials $\left(3^{\text {rd }}\right)$, and Stationary-plant and related operators $\left(16^{\text {th }}\right)$. In the first case, the greatest part of that mobility corresponds to changes to occupations situated above in the occupational ranking while the other two cases refer essentially to downward mobility.

In line with the evidence presented by Cardano et al. (2004) and Fitzenberger and Kunze (2011), the results by gender show that occupational mobility is greater for men. Considering the 26 occupations under analysis, in only 9 of them is the level of mobility higher for 
women. When we perform a separate analysis for upward and downward mobility, we find that the inequality between men and women is more pronounced in the first case, in which women exhibit greater mobility than men in only 9 occupations. In the case of downward mobility, this occurs in 13 occupations.

\section{Determinant factors of occupational mobility in Portugal}

The model

The main goal of our study is to identify the determinants of upward and downward occupational mobility in Portugal, and specifically to investigate the influence of gender on that mobility. To this end, we estimate two logit models. The first seeks to capture the determinants of upward occupational mobility while the other focuses on downward mobility. In the first case, the dependent variable $\left(\mathrm{U}_{\mathrm{it}}\right)$ is defined as follows:

$$
U_{i t}=\left\{\begin{array}{l}
1 \text { if } \operatorname{Rocc}_{i, t}<\operatorname{Rocc}_{i, t-1} \\
0 \text { if } \operatorname{Rocc}_{i, t}=\operatorname{Rocc}_{i, t-1}
\end{array}\right.
$$

where Rocc $\mathrm{i}_{\mathrm{i}, \mathrm{t}}$ is the hierarchical position of the occupation held by worker $i$ in period $t$.

In turn, in the second model the dependent variable is given by:

$$
D_{i t}=\left\{\begin{array}{l}
1 \text { if } \operatorname{Rocc}_{i, t}>\operatorname{Rocc}_{i, t-1} \\
0 \text { if } \operatorname{Rocc}_{i, t}=\operatorname{Rocc}_{i, t-1}
\end{array} .\right.
$$


We consider six groups of explanatory variables: socio-demographic characteristics (gender, age, nationality, marital status, head of the household), human capital (educational attainment level, overeducation/undereducation), firm characteristics (economic sector, size), job characteristics (type of contract, initial occupation), business cycle (unemployment rate), and regional variables. Additionally, we include controls for time effects. Table 3 summarizes the definitions of the explanatory variables.

[Table 3]

Striving for a more detailed assessment of the pattern of occupational mobility, we additionally perform an analysis by quartiles in order to assess whether the determinants of upward and downward mobility vary across the occupational hierarchy. ${ }^{1}$ The partition of the occupations by quartiles leads to the formation of the following groups: occupations from 1 to 12 (fourth quartile), 13 to17 (third quartile), 18 to 23 (second quartile), and 24 to 26 (first quartile). For each of the quartiles we estimate a model corresponding to upward mobility and another to downward mobility. In the models for the extreme quartiles, we adjust the definition of educational levels due to the overrepresentation of lower educational levels in the first quartile and of higher levels in the fourth quartile. Therefore, in the first quartile, we consider three educational levels: primary education - $1^{\text {st }}$ cycle (EDUC1_1); more than primary education $-1^{\text {st }}$ cycle and less than secondary education (EDUC2_1); and secondary education or more (EDUC3_1). In the fourth quartile, we include the following levels: less than secondary education (EDUC1_4), secondary education (EDUC2_4), and tertiary education (EDUC3_4).

\footnotetext{
${ }^{1}$ The quartiles are defined according to the number of people in the occupational classes.
} 
Table 4 shows the results from the estimation of the model presented in the previous section, considering the whole sample. Tables 5 and 6 show, respectively, the results from the models for the extreme quartiles and the intermediate quartiles.

\section{[Table 4]}

[Table 5]

[Table 6]

The evidence presented in these tables leads us to two main conclusions: the occupational mobility patterns are clearly different between men and women, and these patterns are notably less favorable for women.

A more detailed evaluation of the results suggests other important conclusions. First, in the context of the overall model (Table 4), we see that being a woman penalizes upward mobility and favors downward mobility, which is clearly in accordance with the several theoretical arguments discussed above.

Second, considering the evidence in Tables 5 and 6 and focusing specifically on upward mobility, we note that being female works as a penalizing factor when the initial occupation belongs to the lower half of the occupational distribution. This gender difference, favorable to men with regard to the probability of transition to better occupations, lends support to the results obtained by Song and Dong (2011) for the Chinese economy. On the contrary, our evidence suggests that the same effect does not occur when the initial occupation is in the top of the distribution, where there is no statistically significant difference between genders. This result is not surprising. In fact, the theoretical arguments identified above, which generally 
suggest a pattern of upward mobility less favorable for women, appear to be particularly valid when one considers jobs that are not at the top of the occupational ranking. Let us consider the examples of informal networks and the incidence of temporary contracts. It is not likely that men and women working in top occupations have great differences in terms of their network of social contacts. Once they reach these positions, both genders will probably have high density networks of contacts. In the same line of reasoning, the incidence of temporary contracts is more limited when we consider better occupations.

Third, the effect of the female variable on the probability of downward mobility (increasing that probability) occurs in the intermediate quartiles, but the effect is not significant in the extreme quartiles.

Taking these results together, there seems to be a greater tendency for women to remain in the poorer jobs, confirming the idea that there is a considerable gender gap in terms of job quality, as reported, for instance, by Mülhau (2011).

\section{Other determinants of occupational mobility}

Beyond the discussion of gender differences, the evidence presented above emphasizes other critical features. First, being married reduces occupational mobility. This result agrees with the evidence documented by Shin (2005), particularly for women, as well as with the conclusion of Moscarini and Vella (2008) suggesting that occupational mobility falls with family commitments. Second, in line with the results obtained by Aleksynska and Tritah (2011), we conclude that native individuals have an advantage in terms of transitions to better occupations. Similarly, in a study of the integration of immigrants in the Spanish economy, Simón et al. (2011) conclude that they show an occupational downgrading when compared with their origin countries due to the strong initial dip experienced upon arrival and their slow 
improvement in the following years. Our results confirm that natives are less likely to be involved in downward occupational mobility than immigrants, and emphasize that this effect occurs primarily in the top occupations.

Age is usually mentioned as an important determinant of occupational mobility. However, its exact influence is far from consensual in the literature. While Cardano et al. (2004) suggest that age increases the probability of occupational change, the opposite conclusion is obtained by Shin (2005) and Moscarini and Vella (2008). On the other hand, Song and Dong (2011) find no significant impact of age on occupational mobility. In a related strand of literature, some studies suggest that there are significant returns to occupational experience (Kambourov and Manovskii, 2009). Since older individuals are more likely to have more occupationspecific human capital, it is reasonable to assume that they have more to lose with occupational changes. Our evidence sheds some light on the impact of age: (i) in terms of the overall model, age reduces the probability of downward occupational mobility, not affecting the probability of upward mobility; (ii) considering an analysis by quartiles, younger individuals (AGE1 and AGE2) have, in all the quartiles with the exception of the first in which the effect occurs only for AGE2, higher probability of downward mobility; and (iii) in two lower quartiles, the youngest individuals (AGE1) also reveal a higher probability of upward mobility.

Another aspect that should be highlighted from the results shown in Tables 4, 5, and 6 is the importance of the variables related to education. According to, for instance, Dolton and Kidd (1998) and Cardano et al. (2004), education affects occupational mobility positively. Because in the present study we disaggregate the determinants of upward and downward mobility, we obtain three main results: (i) overall, the higher the educational level, the greater the probability of upward occupational mobility and the lower the probability of downward mobility; (ii) the same conclusion is valid in the first, third, and fourth quartiles while in the 
second quartile the effect occurs only in the case of upward mobility; and (iii) overeducation (MATCH2) is an important determinant of upward mobility, while undereducation (MATCH3) is a determinant of downward occupational mobility. This last evidence confirms the conclusions of Longhi and Brynin (2010) in the case of Germany, in which they identify an important effect of educational mismatch in the explanation of the occupational mobility decisions.

Less permanent contracts (CONTRACT2 and CONTRACT3) always increase the probability of moving down in occupational terms, whatever the hierarchical position of the initial occupation. In the lower half of the distribution, the existence of such types of contracts also contributes to increase the probability of upward mobility.

In all quartiles with the exception of the fourth, work in the services sector (SECTOR2) reduces the probability of downward mobility, being the effect more pronounced in the case of the poorest occupations (first quartile). On the other hand, in the top half of the distribution, the probability of upward occupational mobility is greater when the individual works in services.

Additionally, it is possible to conclude that firm size affects the pattern of occupational mobility in the fourth quartile positively (increasing the probability of moving up and decreasing the probability of moving down), while the impact is negative in the occupations situated lower in the occupational ranking (with a lower probability of upward mobility in the second quartile and a higher probability of downward mobility in the first).

On the other hand, periods with higher unemployment rates imply greater (upward and downward) occupational mobility, suggesting a counter-cyclical pattern in the Portuguese economy. This result is in line with the dominant prediction regarding downward mobility but contrasts with the expected impact in the case of upward mobility. 
The consideration of regional variables shows that the probability of occupational mobility, especially upward mobility, is greater in the two most dynamic regions, those with a higher degree of sectoral diversification - Norte and Lisboa.

The initial occupation of the worker is one of the most important determinant factors of the probability of occupational mobility, being the effect stronger in the case of upward mobility. In line with the evidence obtained by Song and Dong (2011), we verify that higher ranked occupations are those in which the probability of upgrading are lower (with the exception of the $3^{\text {rd }}$ occupation of the ranking - Legislators and senior officials), while the opposite occurs in the case of occupations at the lower end of the hierarchy and in the case of individuals working as General managers $\left(11^{\text {th }}\right.$ in the ranking). Regarding downward mobility, the pattern is reversed (higher probability at top occupations and lower at the bottom). The quartile analysis shows that although the initial occupation is a key determinant in every section of the distribution, its importance is more pronounced in the fourth quartile.

\section{Conclusion}

Using data for Portugal, we explored whether the patterns of upward and downward occupational mobility are different between men and women, as suggested by several theoretical approaches. Beyond the overall analysis, we tested if the gender differences also depend on the position of the different occupations in terms of wage ranking. To that end, we developed an analysis by quartiles, discussing the determinants of upward and downward mobility for each of the sections of the occupational hierarchy.

The evidence obtained confirms, on the one hand, the existence of a distinct pattern of occupational mobility between genders and, on the other hand, that these differences depend on the quartile analyzed. Women exhibit a more unfavorable pattern of occupational mobility 
due, essentially, to the disadvantage they have at the bottom of the distribution. In the top occupations, the results suggest the existence of equality between genders.

Beyond these results, findings demonstrate the importance of other occupational mobility determinants. We conclude that: (i) being married reduces occupational mobility; (ii) native individuals show a more favorable pattern of occupational mobility; (iii) age contributes positively to reduce the probability of downward mobility, not affecting the upward probability; (iv) education is a critical determinant of occupational mobility, with higher levels of schooling having a positive impact on the patterns of occupational changes; (v) educational mismatch also influences the decisions of occupational transition; (vi) less stable contracts favor occupational change; and (vii) occupational mobility presents, in Portugal, a counter-cyclical pattern.

This paper suggests further research directions. A first possible extension would be an econometric analysis of the determinants of occupational mobility disaggregating the dependent variable according to the average number of levels that the individuals move up or down, thereby putting the focus on the magnitude of occupational changes. A second interesting topic would be an investigation of the patterns of occupational mobility by initial occupation, seeking to determine the contours of the mobility in each occupation. Finally, the study of the short- and long-term effects for men and women of the decision to change occupation in terms of career, wage, and job security would allow a better understanding of this phenomenon. Answers to these questions are potentially helpful to further explore gender disparities in this area.

\section{Acknowledgements}


The authors are grateful to the Office of National Statistics (INE) for kindly providing us with the survey data and to the financial support from Fundação para a Ciência e para a Tecnologia (PIHM/GC/0115/2008 and PEst-OE/EGE/UI0315/2011). The usual disclaimer applies.

\section{References}

Aleksynska, M. and Tritah, A. (2011) Occupation-education mismatch of immigrant workers in Europe: context and policies. CEPII Working Paper No. 2011-16.

Arulampalam, W. and Booth, A. (1998) Training and labour market flexibility: is there a trade-off? British Journal of Industrial Relations, 36,4, 521-536.

Bergmann, B. (1974) Occupational segregation, wages and profits when employer discriminate by race and sex. Eastern Economic Journal, 1,2, 103-110.

Blackburn, M. (2010) The impact of internal migration on married couples' earnings in Britain. Economica, 77,307, 584-603.

Boyle, P., Cooke, T., Halfacree, K. and Smith, D. (2001) A cross-national comparison of the impact of family migration on women's employment status. Demography, 38,2, 201-213.

Campbell, K. (1988) Gender differences in job-related networks. Work and Occupations, $15,2,179-200$.

Campbell, K. and Rosenfeld, R. (1985) Job search and job mobility: sex and race differences. Research in the Sociology of Work, 3, 147-174.

Cardano, M., Costa, G. and Demaria, M. (2004) Social mobility and health in the Turin longitudinal study. Social Science \& Medicine, 58,8, 1563-1574.

Clark, A. (1997) Why are women so happy at work? Labour Economics, 4,4, 341-372.

Clark, A. (2001) What really matters in a job? Hedonic measurement using quit data. Labour Economics, 8,2, 223-242.

Croson, R. and Gneezy, U. (2009) Gender differences in preferences. Journal of Economic Literature, 47,2, 448-474.

Dex, S., Lindley, J. and Ward, K. (2007) Vertical occupational mobility and its measurement. University of Sheffield Research Paper No. 2007/006. 
Dolton, P. and Kidd, M. (1998) Job changes, occupational mobility and human capital acquisition: an empirical analysis. Bulletin of Economic Research, 50,4, 265-295.

Evans, P. (1999) Occupational downgrading and upgrading in Britain. Economica, 66,261, 76-96.

Fitzenberger, B. and Kunze, A. (2011) Vocational training and gender: wages and occupational mobility among young workers. Oxford Review of Economic Policy, 21,3, 392415.

Frederiksen, A. (2008) Gender differences in job separation rates and employment stability: new evidence from employer-employee data. Labour Economics, 15,5, 915-937.

Harper, B. and Haq, M. (1997) Occupational attainment of men in Britain. Oxford Economic Papers, 49,4, 683-650.

Ioannides, Y. and Loury, L. (2004) Job information networks, neighborhood effects, and inequality. Journal of Economic Literature, 42,4, 1056-1093.

Kambourov, G. and Manovskii, I. (2008) Rising occupational and industry mobility in the United States: 1968-97. International Economic Review, 49,1, 41-79.

Kambourov, G. and Manovskii, I. (2009) Occupational specificity of human capital. International Economic Review, 50,1, 63-115.

Keith, K. and McWilliams, A. (1999) The returns to mobility and job search by gender. Industrial and Labour Relations Review, 52,3, 460-477.

Lalé, E. (2012) Trend in occupational mobility in France: 1982-2009. Labour Economics, $19,3,373-387$.

Longhi, S. and Brynin, M. (2010) Occupational change in Britain and Germany. Labour Economics, 17,4, 655-666.

Martins, P. (2011) Paying more to hire the best? Foreign firms, wages and worker mobility. Economic Inquiry, 49, 2, 349-363.

Moscarini, G. and Thomsson, K. (2007) Occupational and job mobility in the US. Scandinavian Journal of Economics, 109,4, 807-836.

Moscarini, G. and Vella, F. (2008) Occupational mobility and the business cycle. NBER Working Paper No. 13819. 
Mühlau, P. (2011) Gender inequality and job quality in Europe. Management Revue International Review of Management Studies, 22,2, 114-131.

Niederle, M. and Vesterlund, L. (2007) Do women shy away from competition? Do men compete too much? Quarterly Journal Economics, 122,3, 1067-1101.

OECD (2007) Labour Force Survey, OECD, Paris.

Petrongolo, B. (2004) Gender segregation in employment contracts. Journal of the European Economic Association, 2,2-3, 331-345.

Shin, T. (2005) Occupational sex segregation and changes for upward mobility: consequences of job shifts within and across boundaries. Mimeo.

Sicherman, N. and Galor, O. (1990) A theory of career mobility. Journal of Political Economy, 98,1, 169-192.

Simón, H., Ramos, R. and Sanromá, E. (2011) Occupational mobility of immigrants in a low skilled economy: the Spanish case. IZA Discussion Paper No. 5581.

Song, Y. and Dong, X. (2011) Gender and occupational mobility in Urban China during the economic transition. University of Winnipeg: Working Paper No. 2011-01.

Taylor, M. (2007) Tied migration and subsequent employment: evidence from couples in Britain. Oxford Bulletin of Economics and Statistics, 69,6, 795-818.

Tomaskovic-Devey, D. and Skaggs, S. (2002) Sex segregation, labor process organization, and gender earnings inequality. American Journal of Sociology, 108,1, 102-128.

van der Leij, M. and Buhai, S. (2008) A social network analysis of occupational segregation. Fondazione Eni Enrico Mattei: Working Paper 2008-31.

Vieira, J. (2005) Low-wage mobility in the Portuguese labour market. Portuguese Economic Journal, 4,1, 1-14.

Vieira, J. and Madruga, P. (2004) Regions and low wage mobility in Portugal 1996-2000. Regional and Sectoral Economic Studies, 4,2, 41-52.

Wright, E. and Dwyer, R. (2003) The patterns of job expansions in the USA: A comparison of the 1960s and 1990s. Socio-Economic Review, 1,3, 289-325.

Zangelidis, A. (2008) Occupational and industry specificity of human capital in the British labour market. Scottish Journal of Political Economy, 55,4, 420-443. 
Table 1: Occupational ranking - Mean hourly wages by SOC codes

\begin{tabular}{|c|c|c|c|c|}
\hline Ranking & Average & $\begin{array}{l}\text { Standard } \\
\text { deviation }\end{array}$ & $\begin{array}{l}\text { SOC } \\
\text { code }\end{array}$ & Occupation \\
\hline 1 & 10.04 & 5.38 & 12 & Corporate managers \\
\hline 2 & 10.04 & 3.39 & 23 & Teaching professionals \\
\hline 3 & 9.96 & 4.52 & 11 & Legislators and senior officials \\
\hline 4 & 9.81 & 4.83 & 22 & Life science and health professionals \\
\hline 5 & 9.09 & 4.09 & 21 & Physical, mathematical, and engineering science professionals \\
\hline 6 & 8.31 & 3.09 & 33 & Teaching associate professionals \\
\hline 7 & 7.74 & 4.06 & 24 & Other professionals \\
\hline 8 & 6.26 & 2.85 & 34 & Other associate professionals \\
\hline 9 & 5.48 & 2.69 & 31 & Physical and engineering science associate professionals \\
\hline 10 & 5.40 & 2.25 & 32 & Life science and health associate professionals \\
\hline 11 & 5.05 & 3.48 & 13 & General managers \\
\hline 12 & 4.46 & 1.87 & 41 & Office clerks \\
\hline 13 & 4.19 & 2.03 & 42 & Customer services clerks \\
\hline 14 & 3.91 & 1.51 & 72 & Metal, machinery and related trades workers \\
\hline 15 & 3.81 & 1.31 & 83 & Drivers and mobile-plant operators \\
\hline 16 & 3.72 & 1.58 & 81 & Stationary-plant and related operators \\
\hline 17 & 3.53 & 1.20 & 71 & Extraction and building trades workers \\
\hline 18 & 3.43 & 1.21 & 73 & Precision, handicraft, printing, and related trades workers \\
\hline 19 & 3.39 & 1.48 & 51 & Personal and protective services workers \\
\hline 20 & 3.27 & 0.97 & 61 & Market-oriented skilled agricultural and fishery workers \\
\hline 21 & 3.26 & 1.09 & 92 & Agricultural, fishery, and related laborers \\
\hline 22 & 3.14 & 1.20 & 52 & Models, salespersons, and demonstrators \\
\hline 23 & 3.13 & 1.04 & 82 & Machine operators and assemblers \\
\hline 24 & 3.02 & 0.91 & 91 & Sales and services elementary occupations \\
\hline 25 & 2.99 & 0.95 & 93 & Laborers in mining, construction, manufacturing, and transport \\
\hline 26 & 2.81 & 4.36 & 74 & Other craft and related trades workers \\
\hline
\end{tabular}


Table 2: Mobility by initial occupation

\begin{tabular}{|c|c|c|c|c|c|c|c|c|c|}
\hline \multirow[t]{2}{*}{ Rank } & \multicolumn{3}{|c|}{$\begin{array}{c}\text { Mobility } \\
(\%)\end{array}$} & \multicolumn{3}{|c|}{$\begin{array}{l}\text { Upward Mobility } \\
(\%)\end{array}$} & \multicolumn{3}{|c|}{$\begin{array}{c}\text { Downward Mobility } \\
(\%) \\
\end{array}$} \\
\hline & Total & Male & Female & Total & Male & Female & Total & Male & Female \\
\hline 1 & 2.81 & 2.88 & 2.64 & - & - & - & 2.81 & 2.88 & 2.64 \\
\hline 2 & 0.92 & 1.02 & 0.88 & 0.07 & 0.04 & 0.08 & 0.86 & 0.98 & 0.80 \\
\hline 3 & 5.84 & 5.77 & 6.02 & 1.72 & 2.40 & 0.00 & 4.12 & 3.37 & 6.02 \\
\hline 4 & 0.40 & 0.71 & 0.26 & 0.04 & 0.07 & 0.03 & 0.35 & 0.64 & 0.22 \\
\hline 5 & 1.50 & 1.30 & 2.07 & 0.50 & 0.38 & 0.85 & 1.00 & 0.92 & 1.22 \\
\hline 6 & 1.13 & 3.78 & 0.78 & 0.60 & 2.27 & 0.38 & 0.53 & 1.51 & 0.40 \\
\hline 7 & 2.66 & 2.91 & 2.52 & 0.42 & 0.60 & 0.31 & 2.24 & 2.31 & 2.20 \\
\hline 8 & 2.70 & 2.80 & 2.62 & 0.59 & 0.53 & 0.64 & 2.12 & 2.27 & 1.98 \\
\hline 9 & 3.71 & 3.40 & 4.79 & 0.74 & 0.66 & 1.01 & 2.97 & 2.74 & 3.78 \\
\hline 10 & 3.26 & 3.87 & 2.96 & 1.22 & 1.55 & 1.05 & 2.05 & 2.32 & 1.91 \\
\hline 11 & 7.59 & 7.65 & 7.50 & 4.81 & 5.29 & 4.02 & 2.79 & 2.36 & 3.47 \\
\hline 12 & 2.15 & 2.22 & 2.11 & 1.13 & 0.98 & 1.22 & 1.03 & 1.24 & 0.89 \\
\hline 13 & 3.66 & 3.95 & 3.50 & 1.67 & 1.96 & 1.50 & 1.99 & 1.99 & 2.00 \\
\hline 14 & 2.14 & 1.94 & 6.53 & 0.44 & 0.42 & 0.90 & 1.70 & 1.52 & 5.63 \\
\hline 15 & 0.85 & 0.85 & 0.90 & 0.18 & 0.18 & 0.45 & 0.66 & 0.67 & 0.45 \\
\hline 16 & 4.09 & 3.68 & 5.65 & 1.21 & 1.33 & 0.74 & 2.88 & 2.35 & 4.91 \\
\hline 17 & 1.54 & 1.48 & 8.00 & 0.65 & 0.65 & 0.89 & 0.89 & 0.83 & 7.11 \\
\hline 18 & 3.83 & 4.25 & 3.16 & 1.19 & 1.30 & 1.02 & 2.64 & 2.95 & 2.14 \\
\hline 19 & 1.72 & 1.79 & 1.69 & 0.49 & 0.79 & 0.37 & 1.22 & 1.00 & 1.32 \\
\hline 20 & 2.26 & 2.13 & 2.65 & 0.89 & 1.03 & 0.44 & 1.37 & 1.10 & 2.21 \\
\hline 21 & 3.31 & 3.80 & 2.54 & 2.32 & 2.17 & 2.54 & 0.99 & 1.63 & 0.00 \\
\hline 22 & 2.65 & 2.89 & 2.50 & 2.14 & 2.39 & 2.00 & 0.50 & 0.50 & 0.51 \\
\hline 23 & 3.30 & 3.53 & 3.02 & 2.01 & 2.69 & 1.19 & 1.29 & 0.85 & 1.83 \\
\hline 24 & 1.85 & 2.33 & 1.66 & 1.65 & 2.01 & 1.52 & 0.19 & 0.33 & 0.14 \\
\hline 25 & 3.64 & 3.63 & 3.64 & 3.12 & 3.25 & 2.83 & 0.52 & 0.39 & 0.81 \\
\hline 26 & 1.86 & 2.39 & 1.58 & 1.86 & 2.39 & 1.58 & - & - & - \\
\hline
\end{tabular}


Table 3: Definition of the explanatory variables

\begin{tabular}{|c|c|}
\hline Variables & Definition \\
\hline $\begin{array}{l}\text { Gender } \\
\text { (FEMALE) }\end{array}$ & Dummy with value 1 if the individual is a female. \\
\hline $\begin{array}{l}\text { Age groups } \\
\text { (AGE) }\end{array}$ & $\begin{array}{l}\text { Dummies for the following age groups: 15-24 (AGE1); 25-39 (AGE2); 40-54 } \\
\text { (AGE3); and 55-64 (AGE4). }\end{array}$ \\
\hline $\begin{array}{l}\text { Nationality } \\
\text { (NATIVE) }\end{array}$ & Dummy with value 1 for native workers. \\
\hline $\begin{array}{l}\text { Marital status } \\
(\text { MARRIED) }\end{array}$ & Dummy with value 1 if the individual is married. \\
\hline Head (HEAD) & Dummy with value of 1 if the individual is the household's head. \\
\hline Education (EDUC) & $\begin{array}{l}\text { Dummies for the highest level of education attained by the worker: primary } \\
\text { education }-1^{\text {st }} \text { cycle (EDUC1); primary education }-2^{\text {nd }} \text { cycle (EDUC2); lower } \\
\text { secondary education (EDUC3); upper secondary education (EDUC4); and tertiary } \\
\text { education (EDUC5). }\end{array}$ \\
\hline $\begin{array}{l}\text { Education match } \\
\text { (MATCH) }\end{array}$ & $\begin{array}{l}\text { Dummies for the following cases: the individual is adequately educated to perform } \\
\text { the current occupation (MATCH1); overeducated (MATCH2); and undereducated } \\
\text { (MATCH3). }\end{array}$ \\
\hline $\begin{array}{l}\text { Economic activity } \\
\text { (SECTOR) }\end{array}$ & $\begin{array}{l}\text { Dummies for the economic sector of the firm in which the individual works: } \\
\text { industry (SECTOR1); and services (SECTOR2). }\end{array}$ \\
\hline Firm size (SIZE) & $\begin{array}{l}\text { Dummy with value } 1 \text { if the individual works in a firm with more than } 10 \\
\text { employees. }\end{array}$ \\
\hline $\begin{array}{l}\text { Type of contract } \\
\text { (CONTRACT) }\end{array}$ & $\begin{array}{l}\text { Dummies for the following types of contracts: indefinite contract (CONTRACT1); } \\
\text { fixed term contract (CONTRACT2); and other temporary contracts } \\
\text { (CONTRACT3). }\end{array}$ \\
\hline $\begin{array}{l}\text { Initial occupation } \\
\text { (RANKING) }\end{array}$ & $\begin{array}{l}\text { Dummies for the occupations ordered according to Table } 1 \text { (RANKING1 to } \\
\text { RANKING26). }\end{array}$ \\
\hline $\begin{array}{l}\text { Unemployment } \\
\text { rate (UR) }\end{array}$ & Quarterly regional unemployment rates by gender. \\
\hline Region (REG) & $\begin{array}{l}\text { Dummies for the following regions of residence: Norte (REG1), Centro (REG2), } \\
\text { Lisboa (REG3), Alentejo (REG4), and Algarve (REG5). }\end{array}$ \\
\hline
\end{tabular}

Note: Workers were classified as: (i) overeducated if their years of education are above the average of the occupation+standard deviation, and (ii) undereducated if their education is below average-standard deviation. 
Table 4: Determinants of occupational mobility - overall sample

\begin{tabular}{|c|c|c|c|c|}
\hline & \multicolumn{2}{|c|}{ Upward mobility } & \multicolumn{2}{|c|}{ Downward mobility } \\
\hline & Coef & s.e. & Coef & s.e. \\
\hline FEMALE & $-0.239 * * *$ & $(-4.97)$ & $0.159 * * *$ & $(3.00)$ \\
\hline AGE1 & 0.103 & $(1.43)$ & $0.744 * * *$ & $(9.75)$ \\
\hline AGE2 & $-0.083 *$ & $(-1.68)$ & $0.375 * * *$ & (7.39) \\
\hline AGE4 & -0.097 & $(-1.16)$ & -0.139 & $(-1.63)$ \\
\hline NATIVE & $0.376 * * *$ & $(3.00)$ & $-0.250 * *$ & $(-2.04)$ \\
\hline MARRIED & $-0.156 * *$ & $(-2.57)$ & $-0.115^{*}$ & $(-1.81)$ \\
\hline HEAD & 0.078 & $(1.46)$ & -0.088 & $(-1.62)$ \\
\hline EDUC2 & $0.360 * * *$ & $(6.26)$ & $0.114 *$ & $(1.70)$ \\
\hline EDUC3 & $0.569 * * *$ & $(6.01)$ & -0.035 & $(-0.40)$ \\
\hline EDUC4 & $0.990 * * *$ & $(9.86)$ & $-0.365 * * *$ & $(-3.70)$ \\
\hline EDUC5 & $1.943 * * *$ & (12.66) & $-1.125 * * *$ & $(-7.46)$ \\
\hline МАТCH2 & $0.214 * *$ & $(2.38)$ & & \\
\hline МАТСН3 & & & $0.433 * * *$ & $(6.10)$ \\
\hline SECTOR2 & 0.085 & $(1.43)$ & $-0.208 * * *$ & $(-3.85)$ \\
\hline CONTRACT2 & $0.299 * * *$ & $(6.00)$ & $0.563 * * *$ & $(11.13)$ \\
\hline CONTRACT3 & $0.468 * * *$ & $(5.07)$ & $0.648 * * *$ & $(6.75)$ \\
\hline SIZE & 0.067 & $(1.58)$ & -0.0002 & $(-0.00)$ \\
\hline REG2 & $-0.143 * *$ & $(-1.99)$ & $-0.160 * *$ & $(-2.20)$ \\
\hline REG3 & -0.049 & $(-0.92)$ & $-0.212 * * *$ & $(-4.04)$ \\
\hline REG4 & $-0.341 * * *$ & $(-4.61)$ & $-0.506^{* * *}$ & $(-6.60)$ \\
\hline REG5 & $-0.784 * * *$ & $(-10.15)$ & $-0.637 * * *$ & $(-8.55)$ \\
\hline UR & $0.056 * * *$ & $(3.60)$ & $0.060 * * *$ & $(3.82)$ \\
\hline RANKING1 & & & $1.548 * * *$ & $(9.90)$ \\
\hline RANKING2 & $-3.357 * * *$ & $(-7.08)$ & $0.911 * * *$ & $(5.28)$ \\
\hline RANKING3 & 0.229 & $(0.48)$ & $2.029 * * *$ & $(5.72)$ \\
\hline RANKING4 & $-3.735 * * *$ & $(-5.15)$ & -0.137 & $(-0.49)$ \\
\hline RANKING5 & $-1.548 * * *$ & $(-5.04)$ & $0.732 * * *$ & $(3.24)$ \\
\hline RANKING6 & $-1.349 * * *$ & $(-5.63)$ & 0.198 & $(0.84)$ \\
\hline RANKING7 & $-1.515 * * *$ & $(-5.69)$ & $1.379 * * *$ & (10.18) \\
\hline RANKING8 & $-0.441 * * *$ & $(-2.76)$ & $1.060 * * *$ & (11.68) \\
\hline RANKING9 & -0.287 & $(-1.64)$ & $1.128 * * *$ & (11.54) \\
\hline RANKING10 & 0.070 & $(0.27)$ & $1.120 * * *$ & $(5.85)$ \\
\hline RANKING11 & $1.958 * * *$ & (10.95) & $1.112 * * *$ & $(6.11)$ \\
\hline RANKING12 & $0.417 * * *$ & $(3.46)$ & -0.035 & $(-0.41)$ \\
\hline RANKING13 & $0.922 * * *$ & $(6.52)$ & $0.594 * * *$ & $(5.60)$ \\
\hline RANKING14 & -0.201 & $(-1.37)$ & $0.238 * *$ & $(2.55)$ \\
\hline RANKING15 & $-1.054 * * *$ & $(-4.65)$ & $-0.346 * * *$ & $(-2.70)$ \\
\hline RANKING16 & $0.904 * * *$ & $(5.12)$ & $0.860 * * *$ & $(6.84)$ \\
\hline RANKING17 & $0.411 * * *$ & $(3.22)$ & $-0.352 * * *$ & $(-3.22)$ \\
\hline RANKING18 & $0.839 * * *$ & $(4.11)$ & $0.595 * * *$ & $(4.18)$ \\
\hline RANKING20 & $0.931 * * *$ & $(3.59)$ & $0.494 * *$ & $(2.36)$ \\
\hline RANKING21 & $1.883 * * *$ & $(4.40)$ & 0.219 & $(0.37)$ \\
\hline RANKING22 & $1.216 * * *$ & (11.91) & $-0.856 * * *$ & $(-6.39)$ \\
\hline RANKING23 & $1.496 * * *$ & $(12.52)$ & $-0.275^{* *}$ & $(-2.55)$ \\
\hline RANKING24 & $1.427 * * *$ & $(14.88)$ & $-1.596 * * *$ & $(-10.90)$ \\
\hline RANKING25 & $1.930 * * *$ & $(17.09)$ & $-1.050 * * *$ & $(-6.69)$ \\
\hline RANKING26 & $1.490 * * *$ & $(13.66)$ & & \\
\hline Constant & $-5.877 * * *$ & $(-29.41)$ & $-4.317 * * *$ & $(-21.60)$ \\
\hline Time effects & Yes & & Yes & \\
\hline Number of observations & 261,382 & & 237,866 & \\
\hline Pseudo R2 & 0.0814 & & 0.0737 & \\
\hline Log-likelihhod & $-15,202.39$ & & $-14,186.07$ & \\
\hline
\end{tabular}

Notes: (i) Reference category includes: unmarried males, aged 40-54, migrant in the country of work, who are not the household's head, living in Norte, with primary education- $1^{\text {st }}$ cycle, adequately educated, working with an indefinite contract in a firm, operating in industry, with fewer than 11 workers, as a "personal and protective services workers"; (ii) *, **, *** Significant at $10 \%, 5 \%$, and $1 \%$, respectively. 
Table 5: Determinants of occupational mobility - extreme quartiles

\begin{tabular}{|c|c|c|c|c|c|c|c|c|}
\hline & \multicolumn{4}{|c|}{$4^{\text {th }}$ quartile } & \multicolumn{4}{|c|}{$1^{\text {st }}$ quartile } \\
\hline & \multicolumn{2}{|c|}{ Upward mobility } & \multicolumn{2}{|c|}{ Downward mobility } & \multicolumn{2}{|c|}{ Upward mobility } & \multicolumn{2}{|c|}{ Downward mobility } \\
\hline & Coef & s.e. & Coef & s.e. & Coef & s.e. & Coef & s.e. \\
\hline FEMALE & -0.016 & $(-0.15)$ & 0.041 & $(0.54)$ & $-0.214 * * *$ & $(-2.81)$ & 0.073 & $(0.29)$ \\
\hline AGE1 & $-0.392 * *$ & $(-2.04)$ & $0.764 * * *$ & (6.29) & $0.245^{* *}$ & $(2.19)$ & 0.491 & $(1.30)$ \\
\hline AGE2 & $-0.255^{* *}$ & $(-2.47)$ & $0.387 * * *$ & $(5.15)$ & 0.058 & $(0.75)$ & $0.470 *$ & $(1.78)$ \\
\hline AGE4 & 0.182 & $(1.14)$ & -0.180 & $(-1.41)$ & $-0.351 * * *$ & $(-2.60)$ & -0.373 & $(-0.75)$ \\
\hline NATIVE & 0.252 & $(0.60)$ & $-0.551 * * *$ & $(-2.72)$ & $0.466 * *$ & $(2.54)$ & -0.182 & $(-0.37)$ \\
\hline MARRIED & $-0.231 *$ & $(-1.82)$ & $-0.199 * *$ & $(-2.13)$ & -0.070 & $(-0.73)$ & 0.057 & $(0.17)$ \\
\hline HEAD & 0.040 & $(0.36)$ & -0.019 & $(-0.24)$ & 0.056 & $(0.66)$ & -0.072 & $(-0.25)$ \\
\hline EDUC2_4 & $0.523 * * *$ & $(4.70)$ & $-0.296 * * *$ & $(-3.70)$ & & & & \\
\hline EDUC3_4 & $1.169 * * *$ & $(5.08)$ & $-0.887 * * *$ & $(-6.77)$ & & & & \\
\hline EDUC1_1 & & & & & $-0.240 * * *$ & $(-3.09)$ & $-0.492 * *$ & $(-2.04)$ \\
\hline EDUC3_1 & & & & & $0.620 * * *$ & $(5.80)$ & -0.868 & $(-1.64)$ \\
\hline MATCH2 & $0.595 * *$ & $(2.53)$ & & & $0.394 * * *$ & $(4.62)$ & & \\
\hline МАТСН3 & & & $0.739 * * *$ & $(8.63)$ & & & -0.004 & $(-0.01)$ \\
\hline SECTOR2 & $0.432 * * *$ & (3.64) & -0.038 & $(-0.50)$ & -0.054 & $(-0.56)$ & $-1.895 * * *$ & $(-6.90)$ \\
\hline CONTRACT2 & 0.053 & $(0.37)$ & $0.363 * * *$ & $(4.11)$ & $0.382 * * *$ & $(5.13)$ & $0.619 * * *$ & $(2.76)$ \\
\hline CONTRACT3 & 0.332 & (1.14) & $0.607 * * *$ & (3.67) & $0.484 * * *$ & $(3.80)$ & 0.514 & (1.32) \\
\hline SIZE & $0.585^{* * *}$ & $(5.32)$ & $-0.121 *$ & $(-1.74)$ & -0.041 & $(-0.63)$ & $0.598 * *$ & $(2.48)$ \\
\hline REG2 & $-0.550 * * *$ & $(-2.93)$ & -0.125 & $(-1.03)$ & 0.154 & $(1.42)$ & -0.493 & $(-1.47)$ \\
\hline REG3 & $-0.183^{*}$ & $(-1.83)$ & $-0.221 * * *$ & $(-2.98)$ & 0.021 & $(0.22)$ & $-0.517 *$ & $(-1.65)$ \\
\hline REG4 & $-0.596 * * *$ & $(-3.25)$ & $-0.851 * * *$ & $(-6.49)$ & -0.117 & $(-1.05)$ & -0.357 & $(-0.96)$ \\
\hline REG5 & $-0.689 * * *$ & $(-4.02)$ & $-0.702 * * *$ & $(-6.10)$ & $-0.658 * * *$ & $(-5.40)$ & $-1.223 * * *$ & $(-2.97)$ \\
\hline UR & 0.058 & $(1.62)$ & $0.095 * * *$ & $(3.77)$ & $0.050^{* *}$ & $(2.10)$ & -0.012 & $(-0.14)$ \\
\hline RANKING1 & & & $1.322 * * *$ & $(8.82)$ & & & & \\
\hline RANKING2 & $-3.773 * * *$ & $(-7.80)$ & $0.822 * * *$ & $(4.84)$ & & & & \\
\hline RANKING3 & -0.130 & $(-0.27)$ & $1.930 * * *$ & $(5.41)$ & & & & \\
\hline RANKING4 & $-4.054 * * *$ & $(-5.50)$ & -0.236 & $(-0.85)$ & & & & \\
\hline RANKING5 & $-1.654 * * *$ & $(-5.04)$ & $0.626 * * *$ & $(2.82)$ & & & & \\
\hline RANKING6 & $-1.977 * * *$ & $(-8.38)$ & 0.146 & $(0.62)$ & & & & \\
\hline RANKING7 & $-1.729 * * *$ & $(-6.06)$ & $1.219 * * *$ & $(9.38)$ & & & & \\
\hline RANKING8 & $-0.922 * * *$ & $(-6.79)$ & $1.076 * * *$ & $(12.00)$ & & & & \\
\hline RANKING9 & $-0.625 * * *$ & $(-4.05)$ & $1.161 * * *$ & $(12.26)$ & & & & \\
\hline RANKING10 & $-0.484 *$ & $(-1.92)$ & $1.066 * * *$ & $(5.55)$ & & & & \\
\hline RANKING11 & $1.763 * * *$ & $(10.71)$ & $0.926 * * *$ & $(5.08)$ & & & & \\
\hline RANKING24 & & & & & $-0.370 * * *$ & $(-3.43)$ & $0.770 * * *$ & $(2.89)$ \\
\hline RANKING26 & & & & & $-0.367 * * *$ & $(-4.42)$ & & \\
\hline Constant & $-5.577 * * *$ & $(-10.89)$ & $-4.139 * * *$ & $(-14.12)$ & $-3.817 * * *$ & $(-14.23)$ & $-4.900 * * *$ & $(-6.03)$ \\
\hline Time effects & Yes & & Yes & & Yes & & Yes & \\
\hline No. observations & 73,329 & & 76,362 & & 63,124 & & 36,224 & \\
\hline Pseudo R2 & 0.1043 & & 0.0798 & & 0.0406 & & 0.1069 & \\
\hline Log-likelihood & $-3,061.85$ & & $-5,578.80$ & & $-5,946.58$ & & -677.95 & \\
\hline
\end{tabular}

Notes: (i) Reference category is the same as in Table 4 with two exceptions: education and ranking position. Regarding these variables, in the fourth quartile, the reference category includes: individuals with less than secondary education working as "office clerks". In the first quartile, the reference includes workers with more than primary education- $1^{\text {st }}$ cycle and less than secondary education working as "laborers in mining, construction, manufacturing, and transport"; *,**,** Significant at $10 \%, 5 \%$, and $1 \%$, respectively. 
Table 6: Determinants of occupational mobility - intermediate quartiles

\begin{tabular}{|c|c|c|c|c|c|c|c|c|}
\hline & \multicolumn{4}{|c|}{$3^{\text {rd }}$ quartile } & \multicolumn{4}{|c|}{$2^{\text {nd }}$ quartile } \\
\hline & \multicolumn{2}{|c|}{ Upward mobility } & \multicolumn{2}{|c|}{ Downward mobility } & \multicolumn{2}{|c|}{ Upward mobility } & \multicolumn{2}{|c|}{ Downward mobility } \\
\hline & Coef & s.e. & Coef & s.e. & Coef & s.e. & Coef & s.e. \\
\hline FEMALE & -0.232 & $(-1.33)$ & $0.591 * * *$ & $(4.72)$ & $-0.370 * * *$ & $(-4.12)$ & $0.211 * *$ & $(2.03)$ \\
\hline AGE1 & -0.032 & $(-0.16)$ & $0.590 * * *$ & (4.19) & $0.371 * *$ & $(2.57)$ & $0.727 * * *$ & $(4.82)$ \\
\hline AGE2 & -0.199 & $(-1.49)$ & $0.311 * * *$ & $(3.18)$ & 0.073 & $(0.68)$ & $0.279 * * *$ & $(2.64)$ \\
\hline AGE4 & $-0.524 *$ & $(-1.95)$ & -0.244 & $(-1.50)$ & 0.160 & $(0.93)$ & 0.092 & $(0.54)$ \\
\hline NATIVE & $0.608 *$ & $(1.87)$ & -0.020 & $(-0.09)$ & 0.087 & $(0.37)$ & -0.117 & $(-0.50)$ \\
\hline MARRIED & -0.214 & $(-1.20)$ & -0.182 & $(-1.41)$ & $-0.275 * *$ & $(-2.24)$ & 0.055 & $(0.42)$ \\
\hline HEAD & -0.114 & $(-0.76)$ & -0.161 & $(-1.49)$ & $0.310 * * *$ & $(2.95)$ & -0.143 & $(-1.23)$ \\
\hline EDUC2 & $0.620 * * *$ & $(3.91)$ & 0.040 & $(0.37)$ & 0.156 & (1.32) & 0.388 & $(1.40)$ \\
\hline EDUC3 & $0.873 * * *$ & $(2.72)$ & 0.079 & $(0.59)$ & $0.362 * *$ & $(2.20)$ & 0.173 & $(0.61)$ \\
\hline EDUC4 & $1.589 * * *$ & $(5.15)$ & $-0.382 * *$ & $(-2.10)$ & $0.688 * * *$ & $(3.27)$ & 0.082 & $(0.27)$ \\
\hline EDUC5 & $1.893 * * *$ & (3.38) & $-0.945 * *$ & $(-1.98)$ & $1.974 * * *$ & (7.79) & -0.213 & $(-0.43)$ \\
\hline MATCH2 & 0.454 & (1.49) & & & 0.007 & $(0.04)$ & & \\
\hline MATCH3 & & & $0.433 * * *$ & $(3.55)$ & & & 0.400 & $(1.43)$ \\
\hline SECTOR2 & $0.260 *$ & (1.90) & $-0.207 * *$ & $(-2.17)$ & $-0.546 * * *$ & $(-3.45)$ & $-0.368 * *$ & $(-1.96)$ \\
\hline CONTRACT2 & 0.108 & $(0.78)$ & $0.732 * * *$ & $(8.27)$ & $0.440 * * *$ & $(4.61)$ & $0.572 * * *$ & $(5.96)$ \\
\hline CONTRACT3 & -0.092 & $(-0.35)$ & $0.751 * * *$ & (4.84) & $0.719 * * *$ & $(3.67)$ & $0.641 * * *$ & (3.03) \\
\hline SIZE & 0.128 & $(1.15)$ & 0.079 & (0.99) & $-0.142 *$ & $(-1.68)$ & -0.026 & $(-0.29)$ \\
\hline REG2 & $-0.413 * *$ & $(-2.03)$ & -0.048 & $(-0.37)$ & -0.201 & $(-1.43)$ & $-0.270^{*}$ & $(-1.87)$ \\
\hline REG3 & -0.153 & $(-1.11)$ & $-0.252 * *$ & $(-2.31)$ & -0.029 & $(-0.28)$ & -0.095 & $(-0.84)$ \\
\hline REG4 & $-0.665 * * *$ & $(-3.34)$ & $-0.395 * * *$ & $(-2.90)$ & $-0.378 * *$ & $(-2.52)$ & -0.179 & $(-1.24)$ \\
\hline REG5 & $-1.131 * * *$ & $(-5.54)$ & $-0.665 * * *$ & $(-4.64)$ & $-0.772 * * *$ & $(-4.95)$ & $-0.395 * * *$ & $(-2.73)$ \\
\hline UR & $0.137 * * *$ & $(3.32)$ & $0.053 *$ & $(1.81)$ & 0.026 & $(0.79)$ & 0.038 & $(1.25)$ \\
\hline RANKING13 & 0.183 & $(0.60)$ & $0.554 * * *$ & (3.03) & & & & \\
\hline RANKING14 & $-0.866^{* * *}$ & $(-5.84)$ & $0.538 * * *$ & $(5.07)$ & & & & \\
\hline RANKING15 & $-1.647 * * *$ & $(-6.91)$ & -0.020 & $(-0.14)$ & & & & \\
\hline RANKING16 & $0.312 *$ & (1.73) & $1.020 * * *$ & $(7.70)$ & & & & \\
\hline RANKING18 & & & & & 0.168 & $(0.68)$ & $0.565 * * *$ & $(2.65)$ \\
\hline RANKING20 & & & & & $0.716 * * *$ & $(2.71)$ & $0.547 * *$ & $(2.28)$ \\
\hline RANKING21 & & & & & $1.490 * * *$ & (3.34) & 0.109 & $(0.18)$ \\
\hline RANKING22 & & & & & $1.156 * * *$ & (11.02) & $-0.907 * * *$ & $(-6.44)$ \\
\hline RANKING23 & & & & & $0.816^{* * *}$ & (4.33) & -0.273 & $(-1.37)$ \\
\hline Constant & $-6.037 * * *$ & $(-13.26)$ & $-5.032 * * *$ & $(-15.55)$ & $-4.550 * * *$ & $(-12.03)$ & $-4.443 * * *$ & $(-9.47)$ \\
\hline Time effects & Yes & & Yes & & Yes & & Yes & \\
\hline $\begin{array}{l}\text { Number of } \\
\text { observations }\end{array}$ & 64,625 & & 65,054 & & 60,304 & & 60,226 & \\
\hline Pseudo R2 & 0.0945 & & 0.0674 & & 0.0816 & & 0.0448 & \\
\hline Log-likelihood & $-2,285.14$ & & -4213.97 & & -3.774 .47 & & $-3,596.59$ & \\
\hline
\end{tabular}

Notes: (i) Reference category is the same as in Table 4 with one exception: ranking position. Regarding this variable, in the third quartile, the reference category includes individuals working as "extracting and building trades workers". In the second quartile, the reference includes workers working as "personal and protective services workers"; *, **, *** Significant at $10 \%, 5 \%$, and $1 \%$, respectively. 